\title{
Factors Potentially Influencing Discipline Referral and Suspensions at an Affiliated Charter High School
}

\author{
Debra Bryant, EdD \\ Walden University, Minneapolis, Minnesota, United States \\ (iD) https://orcid.org/0000-0001-7835-4122 \\ Andrea Wilson, $\mathrm{PhD}$ \\ Walden University, Minneapolis, Minnesota, United States \\ (iD) https://orcid.org/0000-0002-1471-654X
}

Contact: ddb0437@gmail.com

\begin{abstract}
This article addresses long-standing data from federal government agencies documenting concerns regarding the use of school discipline and suspension indicating that Black students are referred for discipline and/or suspended at a higher rate than students of other ethnicities. Available data from a local school district reflected similar troubling patterns of discipline referral and suspension. The purpose of this study was to determine if variables such as students' ethnicity, socioeconomic status, and gender predicted the likelihood of receiving discipline referrals or being suspended at an affiliated charter high school in a local school district. Guided by Bandura's social learning theory and Skinner's behaviorism, this correlational explanatory quantitative study examined archival school discipline data for 2,536 students enrolled ( $n=1,570$ students who received at least one discipline referral or suspension) during the 2013-2014 school year at a local high school. Binomial logistic regression results showed that Black students from low socioeconomic backgrounds were significantly more likely to be suspended compared to other ethnicities. Negative binomial regression analysis indicated students who were Black, male, and were from low socioeconomic backgrounds were at significantly greater risk of receiving a referral than other ethnicities. These results suggest that by investigating school discipline patterns, disproportionality can be identified and later addressed in a manner that respects unique needs of all students.
\end{abstract}

Keywords: disproportionality; suspension; discipline referrals

Date Submitted: January 28, 2020 | Date Published: May 28, 2020

\section{Recommended Citation}

Bryant, D., \& Wilson, A. (2020). Factors potentially influencing discipline referral and suspensions at an affiliated charter high school. Journal of Educational Research and Practice, 10, 119-128.

https://doi.org/10.5590/JERAP.2020.10.1.08 
Bryant \& Wilson, 2020

\section{Introduction}

The Office of Civil Rights, a subagency of the U.S. Department of Education that is primarily focused on protecting students from discrimination, revealed that school personnel at an affiliated charter high school located in southern California were consistently implementing suspension and expulsion to address behavioral issues at a rate that was higher than expected (U.S. Department of Education and Justice, 2014). Significant concerns were raised with regard to Black students in particular. Specifically, the U.S. Department of Justice Civil Rights Division and the U.S. Department of Education's Office of Civil Rights have recognized that social injustice in schools needs to be addressed; on January 28, 2014, the then U.S. Secretary of Education issued a letter to assist public schools outlining the need to examine their discipline policies (Duncan, 2014). The letter indicated that the disproportionate use of suspension and expulsion for students of color and those with disabilities would be seen as discrimination, and school districts would be subject to civil lawsuits (Epstein, 2014).

The disproportionate discipline of Black students is a problem that affects millions of children and families each year (Hoffmann, 2017; Loveless, 2017). The suspension and expulsion rates for Black students are two to three times higher than the suspension rates for other ethnic groups at the elementary, middle, and high school levels (Bland \& Mitchell, 2018; Morris \& Perry, 2017; Skiba et al., 2012; Sparks, 2018). The increasing use of suspension and expulsion for Black students is concerning because it is unclear if suspensions change students' behavior for the better, improve their attitude toward school, deter them from associating with the wrong crowd, or improve the safety of the school (Rafa, 2018).

In California, every year nearly 366,629 students are suspended, and 9,553 students are expelled, resulting in a suspension rate of $5.7 \%$ and an expulsion rate of .01\% (California Department of Education, 2014). Further review of the state-level data indicates differences in the suspension rates for certain student groups. Black students comprise $6.5 \%$ of total enrollment in California and have a suspension rate of $19 \%$ (California Department of Education, 2014). The present study used a quantitative approach to investigate if factors, such as ethnicity, socioeconomic status, and gender predicted the likelihood of a student receiving a discipline referral or being suspended in a local affiliated charter high school in southern California.

\section{Literature Review}

Discipline in education is rooted in a theoretical framework associated with the social, behavioral, and cognitive sciences (B. N. Smith \& Hains, 2012). Social learning theory explains behavior as an interaction of environmental, behavioral, and cognitive effects (Bandura, 1977). Behaviorism relies heavily on learning new and maintaining existing behavior based on the positive or negative consequences of each act (Skinner, 1938). Consequences are inherently a social learning tool, in that the environment and those who control the environment are responsible to establishing and enforcing consequences. As a result of this overlap, current discipline practices in schools and classrooms can be said to have their roots in social learning theory and behaviorism. Thus, discipline policies guided by these theories should produce equitable application of discipline if all other factors are deemed equal. The presence of disproportionate use of discipline in schools suggests that other factors may be influencing school discipline; these other factors must be investigated.

The disproportionate disciplinary representation of Black students is a growing topic that has permeated the research and professional literature for more than a decade (Bland \& Mitchell, 2018; Lewis et al., 2010; Morris \& Perry, 2017; Skiba et al., 2012; Sparks, 2018). The overrepresentation of Black students in suspension data is a national problem and a disturbing issue for schools across the United States (Bland \& Mitchell, 2018; Loveless, 2017; Sparks, 2018; Stetson \& Collins, 2010). Disciplinary exclusions of students have gained national media attention dating back for nearly a decade, but despite the attention and efforts to 
improve the effectiveness of exclusionary discipline practices remains unclear (Carr, 2010; Rafa, 2018; Schwartz, 2011). Perry and Morris (2014) hypothesized that the negative outcomes of exclusionary practices might have a wider range of consequences than are currently understood suggesting that disciplinary exclusion of students interrupts educational progress, which may lead to disruptive behaviors causing school personnel to label the students as deviants.

The concerns raised with regard to Black students include lower academic achievement, higher dropout rates, and accelerating the path to juvenile offences (Brownstein, 2010; Loveless, 2017). Horner et al. (2010) and others have examined the complex relationships between student behavior, peer status, ethnicity, and gender on decisions about school discipline in an urban public school. While the factors that contribute to the disproportionate representation of Black students in disciplinary procedures are complex and varied, research spanning 2 decades has indicated that Black students, followed by Latino and Native American students, are disciplined at higher rates than students of other ethnicities (Horner, et al., 2010; Losen et al., 2016; Loveless, 2017).

According to Noltemeyer et al. (2015), school administrators have the right and responsibility to use suspensions to ensure the students and staff are safe, students can learn, and teachers can teach. The mildest forms of school discipline are used to ensure that students understand and follow school rules and procedures. The most severe forms of discipline used in schools will exclude students from their classrooms or the campus. When a student is excluded from school, school officials commonly fall prey to the misconception that the suspension will prompt the student to reflect on the situation that led to the suspension thereby preventing a subsequent suspension (Noltemeyer, et al., 2015). Rules and regulations that apply to all students are set forth in schools; however, the challenge for school administrators and educators is how the codes of conduct are administered when they are applied to various student groups including Black students. If the underpinning theories school discipline, namely social learning theory and behaviorism, hold true the application of school discipline procedures should be consistent, predictable, and most importantly equitable across all students. The impetus for this correlational explanatory research study, specifically using an explanatory design, was to ascertain if other variables, such as ethnicity, gender, and socioeconomic status, are mitigating factors for students facing suspension or receiving a discipline referral.

Disproportionate as well as generally high suspension and expulsion rates for students of color are a wellknown, long-term, and continuing problem in American schools (Bland \& Mitchell, 2018; Lewis et al., 2010; Loveless, 2017; Morris \& Perry, 2017; Skiba et al., 2012; Sparks, 2018). The Center for Effective Discipline (2015) has conducted multiple quantitative studies revealing that a discipline gap between White and Black students is present in urban, suburban, and rural schools. Findings showing the overrepresentation of Black students have been consistently documented since the Children's Defense Fund first gathered data in 1975 (Erickson, 2016). These long-standing findings have been reinforced by more current reports which show variables such as students' race and disability status are associated with a greater risk for discipline and suspension (Bland \& Mitchell, 2018; Camacho \& Krezmien, 2019; Sparks, 2018).

Existing studies focus mainly on the disproportionate suspension rates of Black males; however, Black females also suffer from disproportionate suspension, with rates three times higher than their White females (Civil Rights Data Collection, 2014). Likewise, Morris and Perry (2017) showed a suspension rate three times higher for Black females which represented a level commensurate with White male students. Dating back to the time when the U.S. Department of Education's Office of Civil Rights released its scathing report about school discipline practices, Black students comprised $18 \%$ of the nation's student population, but $48 \%$ of those students were suspended from school at least once indicating that Black students were much more likely to be suspended than would be expected (Civil Rights Data Collection, 2014). Essentially, being Black and from a low-socioeconomic household have been shown to be significant factors in predicting discipline outcomes, 
such as being suspended multiple times in the same year (Barrett et al., 2017). Even when policy-driven attempts to reduce suspension are successful overall, the disproportionate suspension persists (Jones, 2017; Trinidad, 2018).

The adverse effects of out-of-school suspension and expulsion are quite profound. The student is often excluded from the instructional program and sent home without any intervention leading to an exacerbation of academic, behavioral, and social problems for the individual student (Hoffmann, 2017; Losen \& Skiba, 2010). According to Losen and Skiba, the removal of students does not change the students' behavior; suspensions are associated with school dropout and juvenile incarceration. The unintended psychological and sociological effects of exclusionary practices on minority students can have significant consequences, depleting a student's sense of school belonging, triggering underperformance in academics, and increasing the likelihood of juvenile delinquency (Hoffmann, 2017). At the same time, research in the field has underscored that schools with higher suspension and expulsion rates are neither safer for students and faculty nor more successful at reducing misbehavior (Lamont et al., 2013; Rafa, 2018). No student, regardless of ethnicity, socioeconomic status, or gender should be targeted to fail in school due to unfair and inequitable discipline practices (M. L. Smith, 2015).

\section{Method}

This correlational explanatory research study was designed to determine if factors such as ethnicity, socioeconomic status, and gender predict the likelihood of a student receiving a discipline referral and of being suspended at an affiliated charter high school in Southern California. Of particular interest was understanding if groups identified in the existing literature as being more vulnerable to receiving school discipline and suspensions were similarly vulnerable in this local school. To inquire about the connections between the variables in this study, the following the research questions and hypotheses were used:

Research Question 1: What factors are important in predicting a student's likelihood of being suspended from an affiliated charter high school?

Null Hypothesis: Factors such as ethnicity, gender, and socioeconomic status are not important when predicting the likelihood of a student being suspended from an affiliated charter high school.

Alternative Hypothesis: Factors such as ethnicity, gender, and socioeconomic status are important when predicting the likelihood of a student being suspended from an affiliated charter high school.

Research Question 2: What are the predictive relationships between ethnicity, gender, and socioeconomic status for the total number of discipline referrals a student will receive?

Null Hypothesis: Ethnicity, gender, and socioeconomic status do not predict the total number of discipline referrals a student will receive.

Alternative Hypothesis: Ethnicity, gender, and socioeconomic status do predict the total number of discipline referrals a student will receive. 
For this analysis, data were accessed from an extant database comprised of detailed information concerning all documented discipline referrals and school suspensions throughout the course of one school year at the local site. The site was an affiliated charter urban high school in Southern California which had approximately 2,536 students enrolled in Grades 9 to 12 during the target school year. Of the enrolled students, 1,570 students (17.4\%) of the total population had at least one discipline referral or one suspension during the target school year. The ages of the students ranged from 13.8 to 19 years old. The composition of the full school enrollment and the final sample were ethnically diverse including approximately 400 students identified as English language learners. Further, approximately half of the student population received free or reduced lunch.

The data were collected through the normal operation of the school during the 2013-2014 school year and maintained in an electronic database for school system use. Prior to gaining access to the archival data set, the district agreed to cooperate with the study and provide access to the data requested. Specific variables were included in the final data set to perform the statistical analysis. Data on the participants' ethnicity, gender, and socioeconomic status were obtained for the final participant sample from one school year.

\section{Results}

The impetus for this correlational explanatory research study was to ascertain if variables, such as ethnicity, gender, and socioeconomic status, are factors that would predict if a student would be suspended and/or receive a discipline referral. That is, were these variables indicative of an increasing the likelihood of a student being suspended or the likelihood of receiving a discipline referral. To answer the first research question, logistic regression was used to predict the likelihood of a student being suspended given additional factors such as their ethnicity, gender, and socioeconomic status. To answer the second research question, negative binomial regression was used to predict the likelihood of a student receiving a discipline referral based on ethnicity, gender, and socioeconomic status.

Overall, the sample of all enrolled students included a slight majority of males, with 1,373 (54.1\%) male students and 1,163 (45.9\%) female students. The sample was majority Hispanic (57.9\%), with the next most common ethnicity being White (20.9\%), followed by Asian (8.9\%), Black (7.6\%), and Filipino (4.7\%). The sample showed that $60.9 \%$ of the students met the criteria to receive free or reduced lunch. When looking at the suspensions, data revealed that $98.2 \%$ of the students had not received a suspension while $1.8 \%$ had received at least one suspension. With respect to discipline referrals, $84.4 \%$ did not receive a referral in the target school year while $15.6 \%$ had received at least one or more discipline referrals in the same time period.

With respect to Research Question 1, the analysis indicated that ethnicity and socioeconomic status were significant predictors of suspension, $\chi^{2}(6)=47.558, p=.000$. Three significant effects emerged in the model. First, Black students were 11.79 times more likely to be suspended than White students. Second, Hispanic students were 2.88 times more likely to be suspended than White students. Third, students from low socioeconomic backgrounds were 2.84 times more likely to be suspended than students with a high socioeconomic background. Gender was not a significant predictor of suspension in this model.

With respect to research question 2, the model representing the predictive relationships between ethnicity, gender, and socioeconomic status and discipline referrals was statistically significant for all variables, $\chi^{2}(6)=$ 491.18, $p<$.001. Specifically, Asian and Filipino students were less likely to receive referrals than White students, while Black and Hispanic students were more likely to receive referrals than White students. Referrals were significantly more numerous for students who were male and for students of low socioeconomic status. Interestingly, of students who received referrals, the chance of suspension increased by 1.15 times for each additional referral received. 
Bryant \& Wilson, 2020

\section{Discussion}

Studies have indicated that the disproportionately high suspension and expulsion rates for students of color are a continuing problem in American schools. The Center for Effective Discipline (2015) has conducted multiple quantitative studies revealing that a discipline gap between White and Black students is present in urban, suburban, and rural schools. However, the studies did not address the factors that may contribute to why students are bring suspended. Therefore, we addressed if various factors such as socioeconomic status, gender, and ethnicity may influence student suspension.

When school discipline is viewed through the framework that grounds this study, the lens of social learning theory and behaviorism, one might expect to see no identifiable differences in behavior patterns, referrals, and suspensions (Kupchik \& Catlaw, 2015). If students were disciplined equally as would be the case if the principles of social learning and behaviorism are at work, minority students would not be disciplined disproportionately (Hoffmann, 2017). Taking that one step further in accordance with the present study's theoretical framework, if students exhibit identical behaviors, then their gender, age, ethnicity, and socioeconomic status should have no connection to disciplinary outcomes. The two research questions in this study were designed to identify potential factors that may play a role in schools having disproportionate discipline data. In other words, looking through the lens of Bandura's social learning theory and Skinner's behaviorism, the findings of this study may help schools to examine internal disciplinary processes, understand relevant patterns, and intervene to reduce the biased application of disciplinary procedures.

\section{Limitations}

There were various limitations presented in this study. One of the limitations was that one affiliated charter high school in Southern California was the focus; therefore, the relevance of the findings may only be applicable to this school or to schools of similar sizes or demographic compositions. In addition, the period was one academic year, which limited how much data could be collected. While the intention of this study was not to generate widely generalizable results, the findings could potentially be generalized to other affiliated charter schools with similar demographics and/or discipline data patterns.

\section{Onward: Further Research}

As a result of this study, the recommendation is for schools to take a deeper look into understanding school discipline. By looking at school discipline patterns from the perspective of social learning theory and behaviorism, inconsistent application of discipline procedures and consequences across students may become evident. If the school discipline policy itself is grounded in theories which assume equitable and consistent outcomes across individuals, as social learning theory and behaviorism would predict, alarm bells should ring when such equity cannot be found in the student data, as was the case in this and too many other studies.

This study looked only at individual student related factors that may be influencing discipline procedures and outcomes. However, there is a need for more research that takes into account aggregate factors at the school and school district levels. For example, schools and school districts which are deemed at risk, low socioeconomic status, low English proficiency, and other broad characteristics may offer meaningful insights into discipline outcomes. By identifying factors that play a role in schools having disproportionate discipline data, the results of this study and future studies like it may help researchers to examine unjust and unequal disciplinary patterns in schools. Further research into the individual student and school oriented factors that influence school discipline offers the opportunity to intervene effectively to reduce the biased application of disciplinary procedures. 
An additional recommendation based on the findings of this study, is for schools to create professional development opportunities to train teachers, administrators, and other staff to provide strategies to address students' academic, social, emotional, and behavioral needs and to gain a better understanding of their cultural differences. There is a need for school personnel to utilize resources, such as school counselors, to create discipline panels that include all stakeholders (e.g., parents, teachers, and other school staff) to create and implement equitable discipline practices. The importance of culturally relevant disciplinary practice needs to be recognized. Specifically, the inclusion of culturally responsive instructional and disciplinary practices is likely to help prepare teachers to make connections with their students' existing mental schemes, learning styles, cultural perspectives, families, and communities (Boneshefski \& Runge, 2014). An associated recommendation is for schools to identify where the district's current practices are in terms disproportionality and provide research-based interventions and tools for addressing students' behaviors which take cultural differences into account.

\section{Conclusion}

This correlational study addressed if factors such as ethnicity, socioeconomic status, and gender predicted the likelihood of a student receiving a discipline referral and of being suspended at an affiliated charter high school in southern California. Based on data analysis, ethnicity, gender, and socioeconomic status are factors that may predict whether a student will receive at least one suspension or at least one discipline referral. Focusing only on demographics and suspension data may not give teachers a comprehensive view of their students. Thus, professional development initiatives that can assist teachers in improving their academic instruction and reducing behavioral issues are needed (Owen et al., 2015). Currently, disparities in suspension rates for students of color suggest the need for training on culturally responsive practices, which could in turn have positive effects on the classroom environment and reduce disruptive behaviors (Owen et al., 2015).

Positive suggestions for the enhancement of society will be to show educators that as society continues to diversify, we have a social responsibility to create classrooms that will meet the needs of diverse students. Many teacher education programs do not prepare sufficiently pre-service teachers to meet the needs of diverse students. The professional literature sets the context for educators that, to meet the needs of diverse students, they must recognize the importance of identity, language, and culture in shaping the way students behave and learn (Heitner \& Jennings, 2016). Furthermore, through better understanding student diversity, educators will be able to help diverse students to achieve academic success while respecting their identities and backgrounds as meaningful opportunities to create optimal learning environments.

\section{References}

Bandura, A. (1977). Social learning theory. Prentice Hall.

Barrett, N., McEachin, A., Mills, J. N., \& Valant, J. (2017). Disparities in student discipline by ethnicity and family income. https://educationresearchalliancenola.org/files/publications/010418BarrettMcEachin-Mills-Valant-Disparities-in-Student-Discipline-by-Race-and-Family-Income.pdf

Bland, E., \& Mitchell, C. (2018). Black students bear uneven brunt of discipline, data show. Education Week. https://www.edweek.org/ew/articles/2018/05/02/black-students-bear-uneven-brunt-ofdiscipline.html

Boneshefski, M. J., \& Runge, T. J. (2014). Addressing disproportionate discipline practices within a schoolwide positive behavioral interventions and supports framework: A practical guide for calculating and using disproportionality rates. Journal of Positive Behavior Interventions, 16(3), 149-158.

Brownstein, R. (2010). Pushed out. Education Digest, 75(7), 23-27. 
California Department of Education. (2014). Expulsion and suspension data. https://www.cde.ca.gov/

Camacho, K. A., \& Krezmien, M. P. (2019). Individual and school-level factors contributing to disproportionate suspension rates: A multi-level analysis of one state. Journal of Emotional and Behavioral Disorders, 27(4), 209-220. https://doi.org/10.1177/1063426618769065

Carr, S. (2010, April 20). Louisiana school suspension, expulsion rates criticized as excessive. https://www.nola.com/education/index.ssf/2010/o4/louisiana_school_suspension_ex.html

Center for Effective Discipline. (2015). Discipline and the Law: State laws. https://www.zeroabuseproject.org/center-for-effective-discipline/

Civil Rights Data Collection. (2014). Data snapshot: School discipline. https://ocrdata.ed.gov/downloads/crdc-school-discipline-snapshot.pdf

Duncan, A. (2014, January 8). Joint “Dear colleague letter.” https://www2.ed.gov/about/offices/list/ocr/letters/colleague-201401-title-vi.html

Epstein, R. A. (2014). Civil rights enforcement gone haywire: The federal government's new school-discipline policy. Education Next, 14(4), 28-33.

Erickson, J. H. (2016). Excluding whom? An examination of ethnicity, gender, \& suspension (Master's thesis). https://soar.wichita.edu/bitstream/handle/10057/12654/t16009 Erickson.pdf?sequence=1\&isAllow $\underline{\mathrm{ed}=\mathrm{y}}$

Heitner, K. L., \& Jennings, M. (2016). Culturally responsive teaching knowledge and practices of online faculty. Online Learning, 2O(4), 54-78.

Hoffmann, F. (2017). From suspended to destitute: The disproportionate effect of out-of-school suspensions on low-income families. Indiana Journal of Law and Social Equality, 5(1), 169-195.

Horner, S. B., Fireman, G. D., \& Wang, E. W. (2010). The relation of student behavior, peer status, race, and gender to decisions about school discipline using CHAID decision trees and regression modeling. Journal of School Psychology, 48(2), 135-161.

Jones, C. (2017). Suspension, expulsion rates fall sharply in California, but racial and ethnic disparities remain. EdSource: Highlighting Strategies for Student Success. https://edsource.org/2017/suspension-expulsion-rates-fall-sharply-in-california-public-schools-butracial-disparities-remain $/ 589722$

Kupchik, A., \& Catlaw, T. J. (2015). Discipline and participation: The long-term effects of suspension and school security on the political and civic engagement of youth. Youth and Society, 47(1), 95-124.

Lamont, J. H., Devore, C. D., Allison, M., Ancona, R., Barnett, S. E., Gunther, R., \& Young, T. (2013). Out-ofschool suspension and expulsion. Pediatrics, 131(3), 1000-1007.

Lewis, C. W., Butler, B. R., Bonner, F. A., \& Joubert, M. (2010). African American male discipline patterns and school district responses resulting impact on academic achievement: Implications for urban educators and policy makers. Journal of African American Males in Education, 1(1), 7-25.

Losen, D. J., Keith, M. A., Hodson, C. L., \& Martinez, T. E. (2016). Charter schools, civil rights, and school discipline: A comprehensive review. https://www.civilrightsproject.ucla.edu/resources/projects/center-for-civil-rightsremedies/schoolto-prison-folder/federal-reports/charter-schools-civil-rights-andschool-discipline-a-comprehensivereview/losen-et-al-charter-school-disciplinereview-2016.pdf 
Losen, D. J., \& Skiba, R. J. (2010). Suspended education: Urban middle schools in crisis. https://www.civilrightsproject.ucla.edu/research/k-12education/school-discipline/suspendededucation-urban-middle-schools-incrisis/Suspended-Education_FINAL-2.pdf

Loveless, T. (2017). 2017 Brown Center Report on American education: Part III race and school suspensions. https://www.brookings.edu/research/2017-brown-center-report-part-iii-race-and-schoolsuspensions/

Morris, E., \& Perry, B. (2017). Girls behaving badly? Race, gender, and subjective evaluation in the discipline of African American girls. Sociology of Education, 9o(2), 127-148. https://doi.org/10.1177/0038040717694876

Noltemeyer, A. L., Ward, R. M., \& Mcloughlin, C. (2015). Relationship between school suspension and student outcomes: A meta-analysis. School Psychology Review, 44(2), 224-240.

Owen, J., Wettach, J., \& Hoffman, K. C. (2015). Instead of suspension: Alternative strategies for effective school discipline. https://law.duke.edu/childedlaw/schooldiscipline/downloads/instead_of_suspension.pdf

Perry, B. L., \& Morris, E. W. (2014). Suspending progress: Collateral consequences of exclusionary punishment in public schools. American Sociological Review, 79(6), 1067-1087.

Rafa, A. (2018, January). Suspension and expulsion: What is the issue and why does it matter? Policy snapshot. Education Commission of the States. https://files.eric.ed.gov/fulltext/ED581500.pdf

Schwartz, A. (2011, July 19). School discipline study raises fresh questions. The New York Times. https://www.nytimes.com/2011/07/19/education/19discipline.html

Skiba, R. J., Shure, L., \& Williams, N. T. (2012). Racial and ethnic disproportionality in suspension and expulsion. In A. L. Noltemeyer \& C. S. McLoughlin (Eds.), Disproportionality in education and special education (pp. 89-118). Charles C. Thomas.

Skinner, B. F. (1938). Behavior of organisms. Appleton-Century-Crofts.

Smith, B. N., \& Hains, B. J. (2012). Examining administrators' disciplinary philosophies: A conceptual model. Educational Administration Quarterly, 48(3), 548-576.

Smith, M. L. (2015). A generation at risk: The ties between zero tolerance policies and the school-to-prison pipeline. McNair Scholars Research Journal, 8(1), 125-141.

Sparks, S. (2018). Suspension rates higher for students of color with disabilities, data show. Education Week. https://blogs.edweek.org/edweek/inside-schoolresearch/2018/04/Civil Rights data discipline gaps special education.html

Stetson, F. H., \& Collins, B. J. (2010). Rethinking suspensions. Principal Leadership, 11(2), 40-44.

Trinidad, J. E. (2018). Structural limitations and functional alternatives reducing suspensions and preserving racial suspension gaps. Race, Ethnicity, and Education. https://doi.org/10.1080/13613324.2018.1538119

U.S. Department of Education and Justice. (2014). U.S. Departments of Education and Justice release school discipline guidance package to enhance school climate and improve school discipline policies/practices. https://www.ed.gov/news/press-releases/us-departments-education-andjusticerelease-school-discipline-guidance-package 
Bryant \& Wilson, 2020

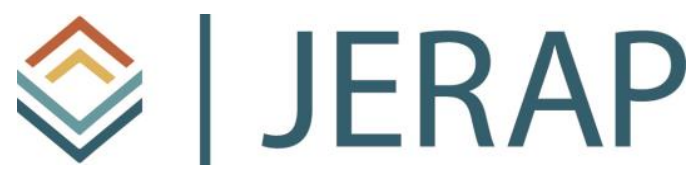

The Journal of Educational Research and Practice is a peerreviewed journal that provides a forum for studies and dialogue about developments and change in the field of education and learning. The journal includes research and related content that examine current relevant educational issues and processes. The aim is to provide readers with knowledge and with strategies to use that knowledge in educational or learning environments. JERAP focuses on education at all levels and in any setting, and includes peer-reviewed research reports, commentaries, book reviews, interviews of prominent individuals, and reports about educational practice. The journal is sponsored by the Richard W. Riley College of Education and Leadership at Walden University, and publication in JERAP is always free to authors and readers. 